\title{
EDITORIAL
}

\section{"NE SUTOR SUPRA CREPIDAM IUDICARET". LA PRÁCTICA Y LA TEORÍA EN LOS DESTINOS DE CONICYT, EN LA OPINIÓN DE UNA REVISTA JURÍDICA DE 40 AÑOS}

Nos enorgullece comenzar las celebraciones del cuadragésimo aniversario de la Revista Chilena de Derecho, por un período que irá desde la presente emisión hasta la del volumen 41 No 1.

En este marco, estamos superlativamente contentos de dar la bienvenida a dos ilustres colegas que se integran a nuestro Comité Editorial, quienes, cierta y ostensiblemente, contribuirán a darle aún mayor realce a esta prestigiosa publicación. El primero de ellos es el Prof. Dr. D. José Luis Cea Egaña, catedrático de Derecho Constitucional, ex Director de esta Revista (1980-1993) y Director del Programa de Doctorado en Derecho de la Pontificia Universidad Católica de Chile. La segunda, es la Profa. Dra. Da. Amelia Castresana, catedrática de Derecho Romano de la Universidad de Salamanca y Directora Académica de los cursos internacionales de Derecho Romano que, desde su Universidad, se imparten bienalmente a centenares de estudiantes chilenos de la licenciatura en Derecho. Agradecemos su enorme generosidad al aceptar, con el mayor entusiasmo, integrarse al equipo de la revista jurídica universitaria más antigua de este país.

Por otro lado, no podemos soslayar el hecho de que esta celebración nos encuentre en una etapa que se prevé de cambios profundos en la institucionalidad de la investigación en Chile -cuyos alcances incluso exceden, creemos, este ámbito de suyo fundamental- ${ }^{1}$.

Como se sabe, la Comisión Nacional de Investigación Científica y Tecnología (CONICYT) es el órgano medular para el desarrollo de la ciencia chilena. Esta corporación fue creada en 1968 para "...asesorar al Presidente de la República en el planeamiento, fomento $y$ desarrollo de las investigaciones en el campo de las ciencias puras y aplicadas" (art. 60 Ley 16.746, de 1968); y, del mismo modo, “... asesorar al Presidente de la República en el planteamiento del desarrollo científico y tecnológico... [para] desarrollar, promover y fomentar la ciencia y tecnología en Chile, orientándolas preferentemente al desarrollo económico y social del pais" (art. 10 DS 491, de 1971).

En lo que atañe más de cerca a nuestro quehacer jurídico, CONICYT impulsa la estandarización y difusión a nivel internacional de nuestras publicaciones periódicas, principalmente a través de su participación en el consorcio SciELO. Asimismo, y especialmente, contribuye de diversos modos y por diversas vías a las investigaciones de los juristas chilenos -cuyos resultados son publicados por nosotros en un número importante-. Entre estos últimos programas competitivos de financiamiento para los investigadores, el de mayor impacto general es, sin duda, FONDECYT (creado por el DL No 33 de 1980); pues -como

1 Véase Legislación fundamental en la Biblioteca del Congreso Nacional, disponible en: http://www. bcn.cl/carpeta_temas/temas_portada.2005-12-27.5502186394/area_2.2005-12-29.3121544639 
consta a todo universitario- ha dado lugar a un círculo virtuoso que sobrepasa la esfera de la investigación y alcanza el rango de estímulo y medida de la calidad de todo el sistema de la educación superior de nuestro país.

Por todo ello, hay muchos ojos observando muy de cerca la idea de hacer una revisión de la institucionalidad chilena en la materia, a través de la creación de una nueva Comisión Asesora Presidencial, según se hizo público en el seno del Consejo Nacional de Innovación para la Competitividad, el 31 de marzo de 2011². Por supuesto, ha sorprendido especialmente -no solo a la ciudadanía, sino que al propio Ministro de Educación, Sr. D. Harald Beyer- ${ }^{3}$ el carácter de premisa inicial adquirido por la idea de trasladar CONICYT desde el Ministerio de Educación al Ministerio de Economía, Fomento y Turismo. Las suspicacias provienen de que el traslado de la adscripción administrativa de CONICYT solo tiene sentido si se planea un cambio radical en su orientación; unido, esto, a las declaraciones del Sr. Ministro de Economía, D. Pablo Longueira, en orden a que con ello se busca "... alcanzar el pleno desarrollo a fines de esta década" ${ }_{4}$, por medio de que "... todos los recursos que se destinan para la investigación en Chile tengan una planificación estatal mucho más vinculante al valor agregado que queremos incorporar a los sectores productivos"s. Por cierto, no es baladí que todo esto se haya puesto en conocimiento del Consejo Nacional de Innovación para la Competitividad; que es también, precisamente, “... una comisión asesora del Presidente de la República... [que tiene] la misión de asesorarlo en la identificación, formulación y ejecución de políticas, planes, programas, medidas y demás actividades relativas a la innovación, incluyendo los campos de la ciencia, la formación de recursos humanos especializados y el desarrollo, transferencia y difusión de tecnologías" (Decreto 1.408, Ministerio de Hacienda, de 2005, artículo 1º). En suma, se prevé por algunos un cambio "economicista", el cual por nosotros al menos es calificado de "reduccionista". Reduccionista, pues, de hecho, las propuestas del Ejecutivo parecieran acercar en demasía las funciones de CONICYT a las de un órgano ya existente -y en buena hora- como, precisamente, el Consejo Nacional de Innovación. Es más, para hacer de estos cuerpos entidades idénticas, bastaría -si no nos equivocamos- con el simple ejercicio de eliminación de competencias de CONICYT; esto es: "... asesorar al Presidente de la República en... el campo de las ciencias purasy aplicadas" (art. 60 Ley 16.746, de 1968); y, “... asesorar al Presidente de la República en el planteamiento del

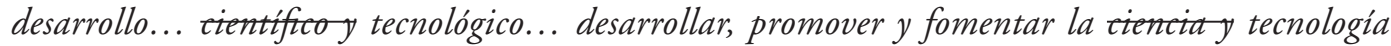
en Chile, orientándolas preferente [ahora: "exclusivamente"] al desarrollo económico y sociat del país" (art. 10 DS 491, de 1971).

\footnotetext{
2 Acta de la 43a Sesión Ordinaria, celebrada el 31 de marzo de 2011, esp. pp. 1 (I. Presentaciones y discusión) y 3 (II. Acuerdos), disponible en: http://www.cnic.cl/images/actas/acta\%20cnic\%20sesion\%20marzo\%202011. pdf

${ }^{3}$ Cfr. La Segunda Online, "Ministro Beyer y comunidad científica rechazan traspaso de CONICYT a Economía", jueves 13 de septiembre de 2012, disponible en: http://www.lasegunda.com/Noticias/Nacional/2012/09/780981/ministro-beyer-y-comunidad-cientifica-rechazan-traspaso-de-conicyt-a-economia

${ }^{4}$ Cfr. http://www.economia.gob.cl/2012/12/06/ministro-longueira-anuncia-creacion-de-una-comision presidencial-para-definir-nueva-institucionalida.htm

5 Cfr. entrevista Diario Financiero, titulada: "Longueira prepara incorporación de Sence y Conicyt al Ministerio de Economía", del 11 de septiembre de 2012, disponible en http://w2.df.cl/longueira-prepara-incorporacion-de-sence-y-conicyt-al-ministerio-de-economia/prontus_df/2012-09-10/211426.html
} 
El 22 de enero de 2013 fue finalmente designada la Comisión Asesora Presidencial a cargo de la tan anunciada revisión ${ }^{6}$. Todos sus integrantes son hombres y mujeres muy notables -qué duda cabe-, sobre los cuales no sería prudente prejuzgar, ni sobre la intensidad con que profesen el oficio universitario ni mucho menos sobre sus sesgos. Nosotros albergamos la esperanza de la extrema prudencia que ya exhibió el propio Consejo Nacional de Innovación ese día 31 de marzo mencionado, al diagnosticar que: "se debe incluir una discusión respecto de la educación superior universitaria, ya que se estima que no puede ser tratada de manera independiente del tema de la ciencia y la tecnología".

Como interesados directos en esta discusión, solo nos permitimos un consejo para esta nueva Comisión Asesora Presidencial: leer con atención el ensayo de Kant titulado Sobre el dicho popular: 'eso puede ser correcto en la teoría, pero no sirve para la práctica ${ }^{8}$; del cual destacamos solo un párrafo: "Por lo tanto, nadie puede considerarse erudito en una ciencia por la práctica y a la vez despreciar la teoría, sin que se muestre simplemente como un ignorante en su área: al turno que se cree capaz, por medio de experimentos y experiencias a ciegas, de ir más allá que lo que la teoría lo puede llevar en su asunto, sin recogerlo en principios determinados (que verdaderamente constituyen lo que se llama teoría) y sin haberlo pensado en un conjunto (lo cual, si al mismo tiempo hay un procedimiento metódico, se dice sistema)"'.

Todos los altos miembros de la Comisión Asesora Presidencial seguramente tendrán muy claro por qué trascendió con tal fuerza el adagio escrito -no intencionalmente como tal- por Plinio, El Viejo: Ne sutor supra crepidam iudicaret" ("que el zapatero no juzgue más arriba del zapato").

Prof. Patricio-Ignacio Carvajal Pontificia Universidad Católica de Chile

\footnotetext{
${ }^{6}$ Cfr. http://www.corfo.cl/sala-de-prensa/comunicados/comunicados-de-prensa/gobierno-anuncia-integrantesde-comision-asesora-presidencial-en-ciencia-tecnologia-e-innovacion

7 Acta de la 43a Sesión Ordinaria, celebrada el 31 de marzo de 2011, esp. p. 1.

8 Kant (1992, pero 1793): "Über den Gemeinspruch: Das mag in der Theorie richtig sein, taugt aber nicht für die Praxis", en: Über den Gemeinspruch: Das mag in der Theorie richtig sein, taugt aber nicht für die Praxis I Zum ewigen Frieden/: ein philosophischer Entwurf, mit Einl. und Anm., Bibliogr. und Reg. kritisch hrsg. von Heiner F. Klemme, Philosophische Bibliothek Band 443, Meiner Verlag, Hamburg, pp. 3-47.

9 "Es kann also niemand sich für praktisch bewandert in einer Wissenschaft ausgeben und doch die Theorie verachten, ohne sich bloß zu geben, daß er in seinem Fache ein Ignorant sei: indem er glaubt, durch Herumtappen in Versuchen und Erfahrungen, ohne sich gewisse Prinzipien (die eigentlich das ausmachen, was man Theorie nennt) zu sammeln und ohne sich ein Ganzes (welches, wenn dabei methodisch verfahren wird, System heißt) ïber sein Geschäft gedacht zu haben, weiter kommen zu können, als ihn die Theorie zu bringen vermag". Cfr. Kant (1992, pero 1793) p. 4.

10 Plinius, Naturalis Historia 35.85.
} 